\title{
Successful polymer flooding and surfactant-polymer flooding projects at Shengli Oilfield from 1992 to 2012
}

\author{
Changhong Gao $\cdot$ Jing Shi $\cdot$ Fangjian Zhao
}

Received: 26 May 2013/Accepted: 5 July 2013/Published online: 19 July 2013

(C) The Author(s) 2013. This article is published with open access at Springerlink.com

\begin{abstract}
Shengli Oilfield, located in Northeast China, is one of the largest and oldest oilfields in China. The field production peaked in 1991 and the overall water cut has reached $95 \%$ in 2012. The decline in production and the increasing demand for fossil energy have motivated the Shengli Oilfield Company (SLOF) to seek feasible enhanced oil recovery methods. Since 1992, more than 60 units at Shengli field have received injection of polymer or a combination of polymer and low-concentration surfactants. Partially hydrolyzed polyacrylamide and petroleum sulfonate were chosen for most polymer flood projects. Field cases demonstrated that polymer flood and surfactant-polymer flood could effectively increase oil rate, decrease water cut and improve oil recovery. This paper reviews several unique field trials at Shengli Oilfield. The earlier polymer flood projects targeted relatively ideal reservoirs with low temperature and low water salinity. However the undergoing polymer flood projects and future projects have to face very challenging reservoir conditions. Loss of polymer viscosity and reservoir heterogeneity affect the success of polymer flood projects. Future research at SLOF will focus on developing more tolerant polymers and improving the flow of polymer in reservoirs.
\end{abstract}

Keywords Enhanced oil recovery $\cdot$ Polymer flood . Heavy oil

C. Gao $(\bowtie) \cdot$ J. Shi $\cdot$ F. Zhao

Sinopec Shengli Oilfield Company, Dongying 257000,

Shandong, China

e-mail: 237184689@QQ.com

\section{Introduction}

Shengli Oilfield, discovered in 1961, is mainly located in the Shandong province in Northeast China. The field is divided into 11 smaller fields, namely Shengcai, Dongxin, Xianhe, Gudao, Gudong etc. The annual field production peaked at 33.55 million tons in 1991. Now the production declines to around 27 million tons per year in 2012, while the overall water cut at Shengli Oilfield has reached $95 \%$.

Several decades ago, the company management realized the field has to rely on enhanced oil recovery (EOR) methods to battle decline and prolong the field's productivity. Moreover, China's thirst for energy has pressurized the company to seek feasible technologies that enhance oil production.

At Shengli field, EOR field pilot with polymer injection was first initiated in 1990. Continuous efforts resulted in great successes. Currently, EOR methods contribute to around 3 million tons of oil production annually at Shengli field, weighing around $11 \%$ of the total oil output at the field. Till November 2012, polymer flooding and surfactant-polymer (SP) flooding methods have contributed to more than 22 million tons of oil production accumulatively, among which polymer flooding achieved the majority of 17 million tons of output. Some unique field cases are described in the following section.

\section{Materials and methods}

The mechanisms of polymer flood have been described in several books (Green and Willhite 1998; Sheng 2010), therefore not repeated here. The most widely used polymer for EOR projects is partially hydrolyzed polyacrylamide (HPAM) due to low cost and good solubility in water. Its molecular structure is given in Fig. 1.

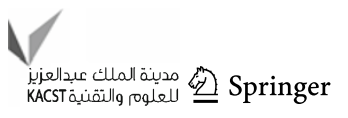




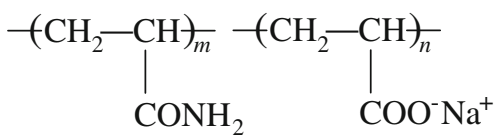

Fig. 1 Molecular structure of HPAM

Table 1 Specifications of HPAM for tertiary recovery

\begin{tabular}{lr}
\hline Parameter & Criteria \\
\hline Degree of hydrolysis (\%) & $\leq 25.0$ \\
Apparent viscosity (cP) & $\geq 11.5$ \\
Filtration ratio & $\leq 2.0$ \\
Screen factor & $\geq 30.0$ \\
Dissolve time (h) & $\leq 2.0$ \\
Content of particles less than $0.15 \mathrm{~mm}(\%)$ & $\leq 5.0$ \\
Content of particles more than $1.0 \mathrm{~mm}(\%)$ & $\leq 5.0$ \\
Viscosity retention after shearing $(\%)$ & $\geq 80.0$ \\
Viscosity retention after static adsorption $(\%)$ & $\geq 80.0$ \\
Viscosity retention after 1 month at $70{ }^{\circ} \mathrm{C}(\%)$ & $\geq 90.0$ \\
Viscosity retention after 3 months at $70{ }^{\circ} \mathrm{C}(\%)$ & $\geq 80.0$ \\
\hline
\end{tabular}

The properties of injected polymer play an important role in the success of polymer flood projects. The chosen polymer must satisfy a few requirements, including good solubility in water and good injectivity. Moreover, polymer solution must maintain a relatively high viscosity under the influences of temperature, shearing, water salinity, and hardness.

Based on experiences at Shengli Company, HPAM products must go through series of screening tests before being deployed in the field. Sample tests and criteria are given in Table 1. For this example, the temperature of the target reservoir was $70^{\circ} \mathrm{C}$, and the formation water salinity was around 10,000 mg/L. Accordingly, the screening tests were conducted under such conditions.

The criteria in Table 1 are explained as follows. (1) The degree of hydrolysis should be $<25 \%$. High degree of hydrolysis will lead to high adsorption of HPAM in porous rock. (2) The HPAM solution must have good filterability to ensure good injectivity. Standard filterability test was conducted at $0.2 \mathrm{MPa}$ constant pressures on a $0.22 \mu \mathrm{m}$ nucleopore filter membrane. (3) HPAM powder should be able to quickly dissolve in base water and form a uniform solution. (4) HPAM solution must maintain good stability and viscosity under the influences of shearing, heating, water salinity, and hardness.

Recent research on improving the performance of polymer flood focuses on two aspects. The challenging reservoir conditions, such as high temperature and high salinity drove researchers to improve the performance of polymers. KYPAM is a modified HPAM product. Its Chinese name indicates good stability in high salinity.
Table 2 Specification of surfactant for tertiary recovery

\begin{tabular}{ll}
\hline Evaluation items & Criteria \\
\hline $\mathrm{pH}$ & $7.0-9.0$ \\
Static adsorption, $\mathrm{mg} / \mathrm{g}$ of sand & $\leq 2.0$ \\
IFT of $0.4 \%$ surfactant solution $(\mathrm{mN} / \mathrm{m})$ & $\leq 5 \times 10^{-3}$ \\
IFT after static adsorption $(\mathrm{mN} / \mathrm{m})$ & $\leq 1 \times 10^{-2}$ \\
Concentration required to achieve ultra-low IFT $(\%)$ & $0.1-0.6$ \\
Viscosity retention of polymer-surfactant mixture $(\%)$ & $\geq 95.0$ \\
\hline
\end{tabular}

Indeed, this comb shaped polymer showed much higher viscosity than HPAM products under higher salinity (Luo et al. 2004). KYPAM has achieved successful field applications in Daqing and Shengli fields (Li 2004).

On the other hand, surfactant flood enhances oil recovery by reducing interfacial tension. Combining polymer flood and surfactant flood can result in even better recovery (Wang et al. 2009; Sheng 2010). The primary surfactant used for SP flood is Shengli petroleum sulfonate (SLPS) which contains $31.4 \%$ active ingredient. To achieve ultralow oil-water interfacial tension under different reservoir conditions, SLPS is often mixed with a variety of complementary surfactants of different types and structures (Wang 2007). The technical requirements of surfactants for tertiary recovery are listed in Table 2 .

Operation of polymer flood is very similar to water flood. It does not require modification to the current water flood facilities. At Shengli field, the polymer is first mixed with fresh water to a concentration of 5,000 ppm, then diluted to the designed polymer concentration and injected.

\section{Field results}

Since 1990, polymer flood and SP flood have been applied in a few field pilots and expanded field tests. In this section, several typical field cases carried out at Gudao and Gudong fields are reviewed. These two fields contain heavy oil, while application of polymer flood in heavy oilfield is a

Table 3 Typical reservoir parameters for Gudao field

\begin{tabular}{ll}
\hline Reservoir depth $(\mathrm{m})$ & 1,230 \\
Reservoir thickness $(\mathrm{m})$ & $7.9-30.5$ \\
Original reservoir pressure $(\mathrm{MPa})$ & 12.5 \\
Reservoir temperature $\left({ }^{\circ} \mathrm{C}\right)$ & 71 \\
Reservoir porosity & 0.335 \\
Reservoir permeability $(\mathrm{md})$ & 1,800 \\
Oil density at surface $(\mathrm{g} / \mathrm{mL})$ & 0.92 \\
Oil viscosity at surface $(\mathrm{cP})$ & $1,475-3,875$ \\
Oil viscosity in situ $(\mathrm{cP})$ & $50-150$ \\
Produced water salinity $(\mathrm{mg} / \mathrm{L})$ & 3,900 \\
\hline
\end{tabular}


Fig. 2 Production history of Gudao ZYQ unit

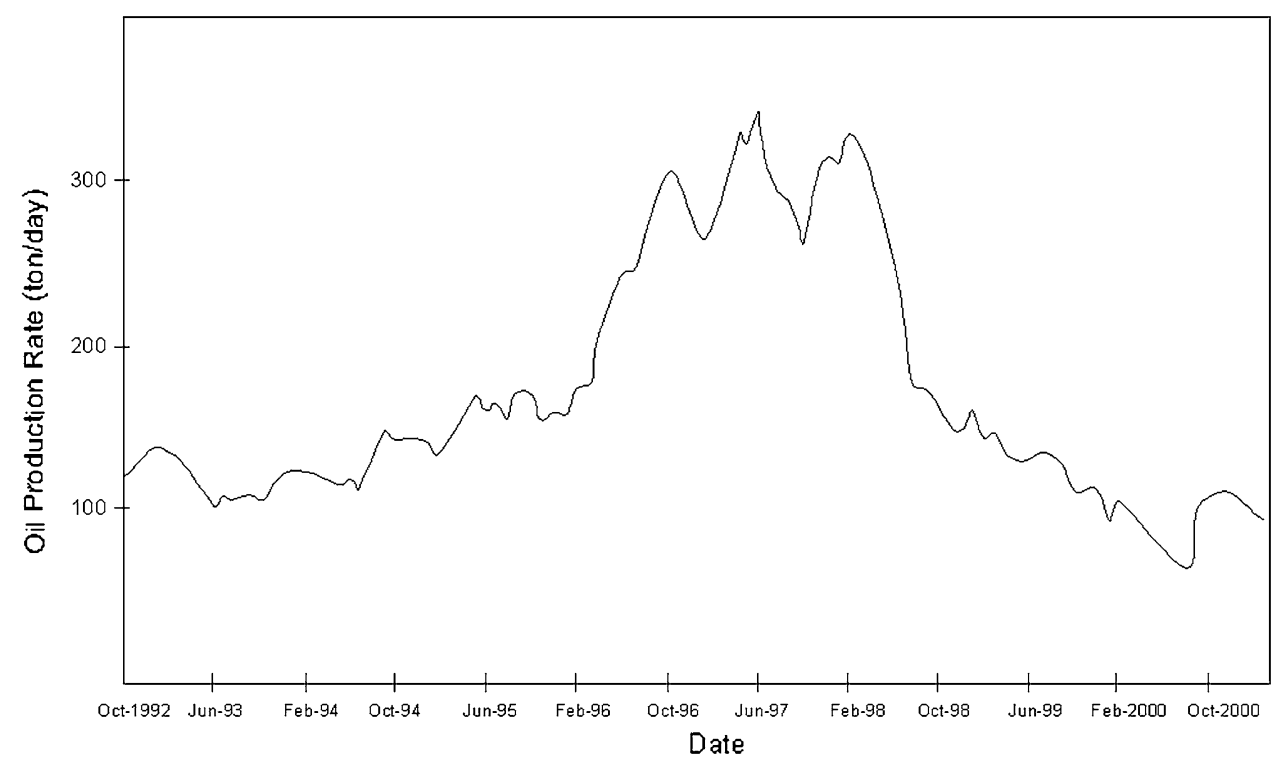

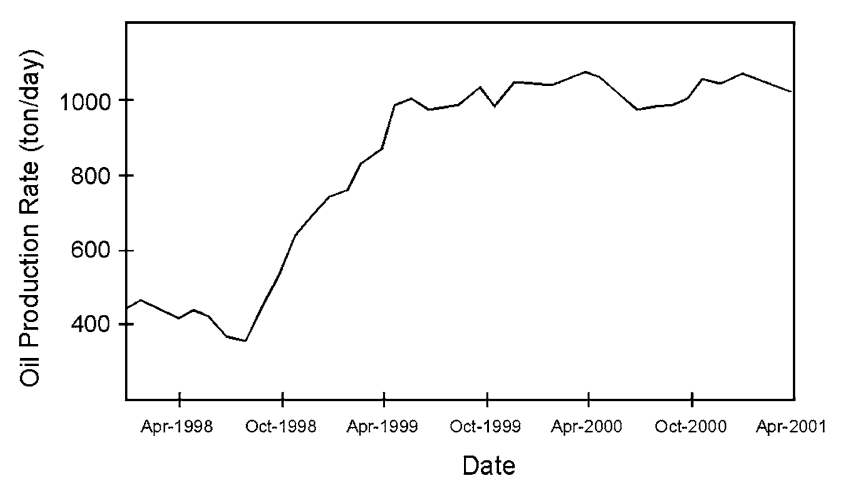

Fig. 3 Production history of Gudao ZENZ unit

particularly challenging topic (Wassmuth et al. 2009; Morel et al. 2010). Very few such field trials have been carried out (Gao 2010). More than 60 units/blocks at Shengli field received polymer injection. Some unique field cases are described here.

\section{Gudao field cases}

The Gudao field is an unconsolidated sandstone reservoir buried at 1,230 m underground. The field was put on production in 1975. The reservoir parameters are listed in Table 3 . Till 2008 , the oil recovery was only $16.5 \%$ after water flood, while the overall water cut has reached $97 \%$. The low secondary recovery was due to the high oil viscosity. The viscosity of injected water was much lower than that of crude oil. As a result, water flood could not mobilize the viscous crude oil. Actually even for polymer flood, the viscosity of polymer solution is much lower than the crude oil viscosity, which presents a major challenge for effective displacement. Nevertheless, the reservoir temperature and salinity are low, which is ideal for polymer flooding.
At Gudao field's ZYQ unit, a polymer pilot was executed in 1992 (Sun et al. 2002). The original oil in place (OOIP) of the unit was 1,650 thousand tons. After polymer injection was started, the oil production rate increased steadily from 120 ton/day in 1992 to 330 ton/day in 1997, as seen in Fig. 2. At the mean time, the water cut declined from 90 to $68 \%$. Routine water flood followed injection of polymer solution. Oil production started to decline in 1998, after the oil bank was produced. Polymer injection recovered 181 thousand tons of tertiary oil. After this successful pilot, polymer flood was extended to several units in the Gudao field.

At Gudao field's ZENZ unit, a polymer pilot was implemented since 1998 (Sun et al. 2002). The OOIP of the unit was 11,850 thousand tons. After polymer injection was started, the oil production rate increased continuously from 420 ton/day in 1998 to 1,000 ton/day in 1999 . At the mean time, the water cut declined from 95 to $82 \%$. Polymer injection recovered 490 thousand tons of extra oil production. The effect of polymer injection maintained for more than 2 years, as seen in Fig. 3.

At Gudao field's ZEB unit, polymer injection started in late 2005. The OOIP of the unit is 15,900 thousand tons. The unit employs 56 injectors and 79 producers. Till the end of 2012, 0.59 PV of polymer fluid has been injected. After polymer injection, the unit's production rate increased continuously and peaked at 820 ton/day in 2010 , as presented in Fig. 4. The water cut dropped from 95 to $88 \%$. The cumulative tertiary oil production and tertiary recovery were 853 thousand tons and $5.4 \%$, respectively.

At Gudao field's Dong unit, a polymer-surfactant flooding project was initiated in mid 2008. The OOIP of the unit was 14,670 thousand tons. The unit is produced from 84 production wells. Till the end of 2012, 0.4 PV of 
Fig. 4 Production history of Gudao ZEB unit

Fig. 5 Production history of Gudao Dong unit

polymer solution has been injected through 55 injection wells. The injected polymer concentration was kept at 2,000 ppm, which resulted in a polymer viscosity of 25-35 $\mathrm{cP}$ at injector wellhead. The oil production rate increased steadily from 187 to 872 ton/day, while the water cut decreased from 97 to $84 \%$. The production trend is given in Fig. 5. So far, the total incremental oil production exceeded 0.5 million tons, equivalent to $3.7 \%$ of oil recovery. After polymer flood, water flood is designed to resume in 2015.

Gudong field pilots

Gudong field is an unconsolidated sandstone reservoir that contains heavy oil. The field was first put into production in 1986. The detailed reservoir data is given in Table 4 (Wang and Zeng 2008). The reservoir oil was rather heavy, but the
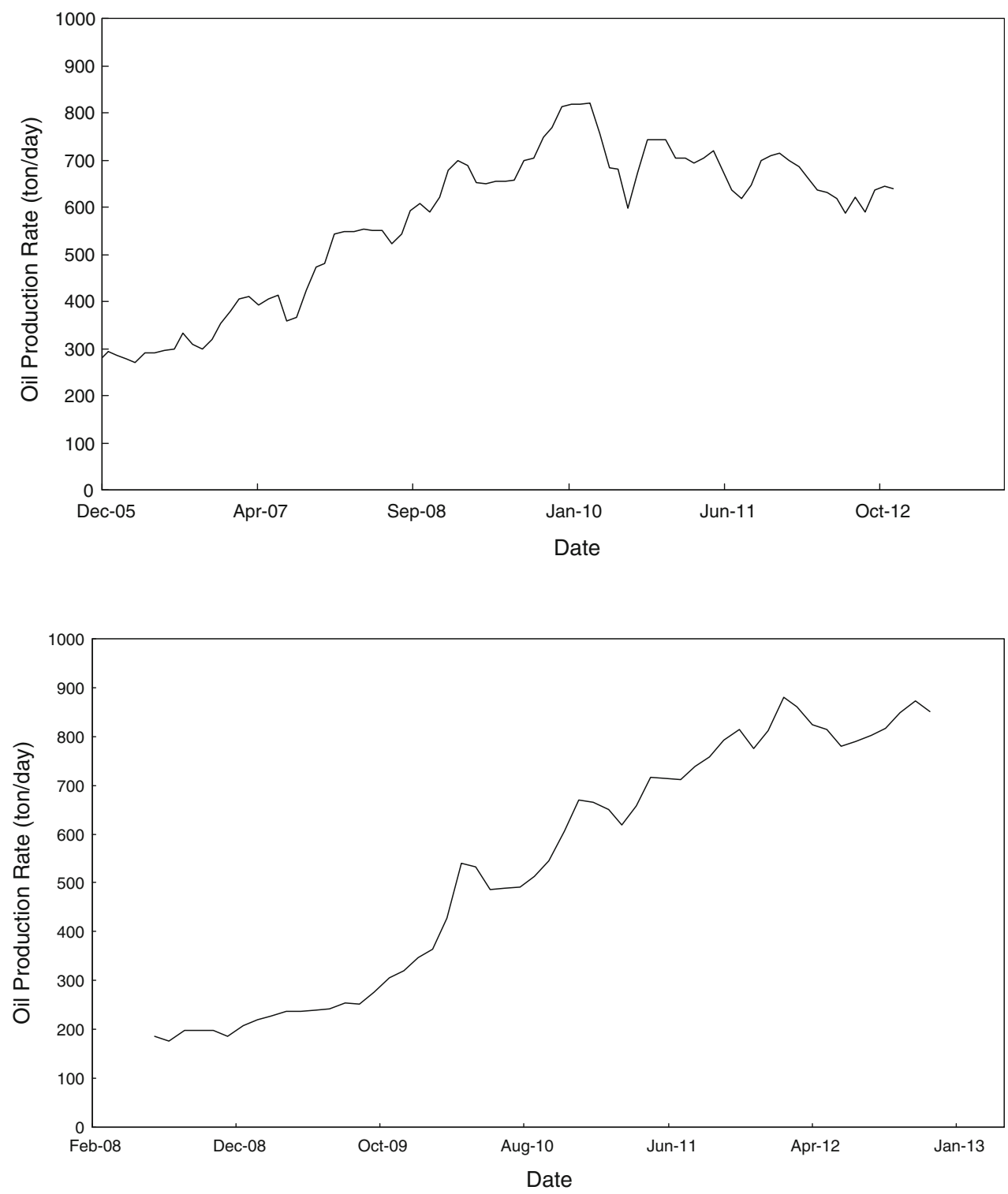

Table 4 Typical reservoir parameters for Gudong field

\begin{tabular}{ll}
\hline Reservoir depth $(\mathrm{m})$ & 1,261 \\
Reservoir thickness $(\mathrm{m})$ & 12.3 \\
Reservoir temperature $\left({ }^{\circ} \mathrm{C}\right)$ & 65 \\
Reservoir porosity & 0.34 \\
Reservoir permeability $(\mathrm{md})$ & 1,230 \\
Oil density at surface $(\mathrm{g} / \mathrm{mL})$ & 0.953 \\
Oil viscosity at surface $(\mathrm{cP})$ & 350 \\
Oil viscosity in situ $(\mathrm{cP})$ & 45 \\
Produced water salinity $(\mathrm{mg} / \mathrm{L})$ & 8,207 \\
Produced water hardness $(\mathrm{mg} / \mathrm{L})$ & 231 \\
\hline
\end{tabular}

reservoir temperature and water salinity were relatively low. Polymer flood may be a feasible technique for this field.

In 1992, the first alkali surfactant polymer (ASP) flood was piloted at Gudong. The secondary recovery before the 
Fig. 6 Production history of Gudong No. 8 unit

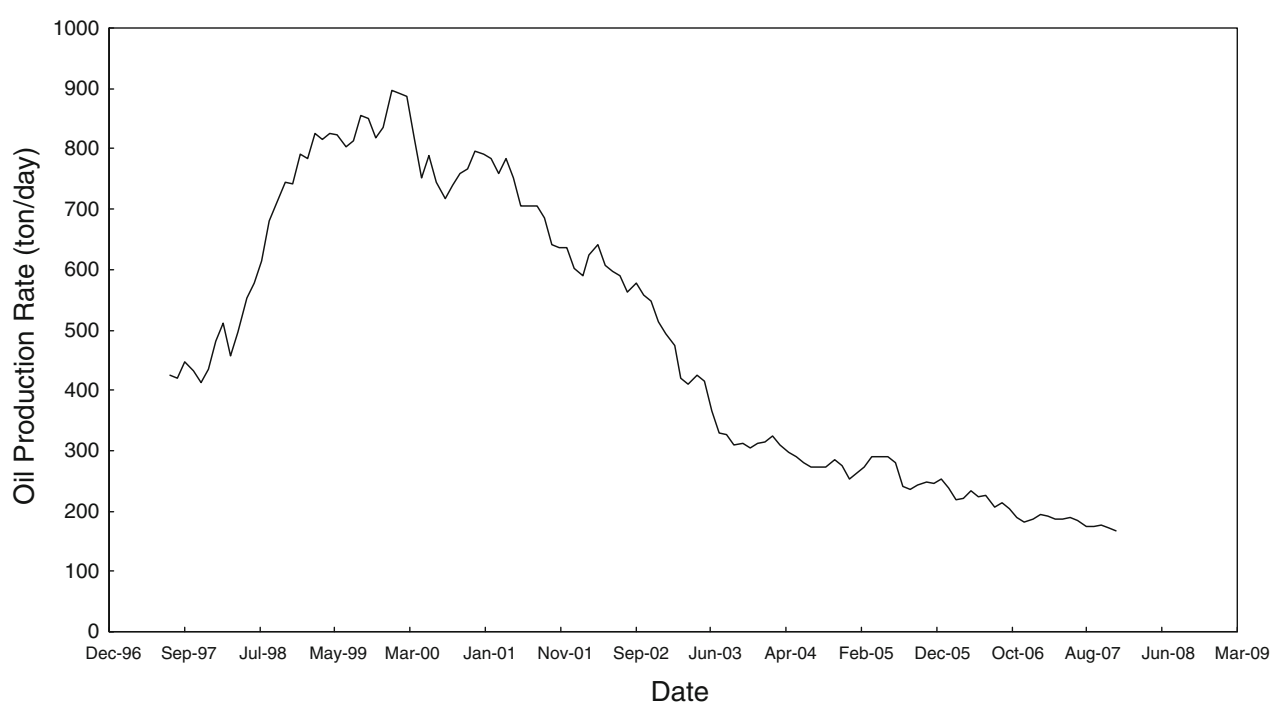

Table 5 Basic information of Gudong QQX unit

\begin{tabular}{ll}
\hline Productive area $\left(\mathrm{km}^{2}\right)$ & 0.94 \\
OOIP (ton) & $2,770,000$ \\
Number of injectors/producers & $9 / 16$ \\
Oil rate before SP flood (ton/day) & 35 \\
Water cut before SP flood (\%) & 98 \\
\hline
\end{tabular}

pilot was already as high as $54 \%$, but ASP flood increased the final recovery to $67.4 \%$. However, severe scale problem occurred and ASP flood was later abandoned. After lab tests and field trials, SP flood proved suitable for Gudong field.

At Gudong's No. 8 unit, polymer flood was implemented in 1998. The oil production rate before the polymer treatment was at 400 ton/day. Since the injection started, the oil rate climbed continuously to 900 ton/day in 2000, while the water cut reduced from 92 to $79 \%$. The production data is given in Fig. 6 .

At Gudong's QQX unit, SP flood was started in 2004 and completed in 2008 (Wang et al. 2010). Some important field data is given in Table 5. In 2004, after $0.12 \mathrm{PV}$ of surfactant and polymer solution was injected, the oil rate started to increase and the water cut began to decline. Till 2006,14 out of 16 production wells showed increase in oil rates. The daily oil rate increased from 35 to 195.7 ton, while the water cut declined to $86 \%$. Till 2007 , all production wells in the unit saw increase in oil rates.

At Gudong field's 34 unit, SP flood was initiated in late 2006. Till December 2012, 0.6 PV of polymer fluid has been injected. The oil rate increased from 390 to 1,169 ton/ day, while the water cut dropped from 95.7 to $87.2 \%$, as seen in Fig. 7. Till the end of 2012, the cumulative tertiary oil production stood at 1,163 thousand tons, while the tertiary recovery reached $5.5 \%$ OOIP.
Shengtuo field pilot

Shengtuo field came online in 1964. Water flood began in 1967. Polymer flood project at Shengtuo field is particularly challenging because of high oil viscosity, high reservoir temperature and high salinity of formation water. Moreover, the salinity of injected water was also high because of lack of fresh water. The detailed reservoir parameters can be found in Table 6. Before polymer flood was initiated in 2002, the oil recovery was $31 \%$ OOIP, while the water cut was as high as $95 \%$ (Li 2004).

At Shengtuo's No. 1 unit, polymer injection was started in March 2002. Considering the unfavorable reservoir conditions, KYPAM was selected as the polymer product. The injection process was designed to take three phases. The first phase was to inject a slug with high polymer concentration $(1,800 \mathrm{mg} / \mathrm{L})$, and the polymer concentration was reduced to 1,400 and $1,000 \mathrm{mg} / \mathrm{L}$ in the second and third phase, respectively. The polymer viscosity at injection wellhead ranged from 30 to $50 \mathrm{cP}$ during most of the operation time.

The oil rate responded positively to polymer injection, as seen in Fig. 8. At the mean time, water cut decreased to $82 \%$. At Shengtuo's SEQ12 unit, SP flood was implemented from early 2009 . The oil rate climbed steadily from 20 to 70 ton/day, while the water cut declined from 98 to $92 \%$. This project is expected to complete in late 2013.

\section{Discussion}

Many factors determine the success of polymer flood projects. First, injected polymer solution must maintain a high viscosity to mobilize the crude oil inside reservoir. Second, reservoir heterogeneity has negative impact on 
Fig. 7 Production history of Gudong 34 unit

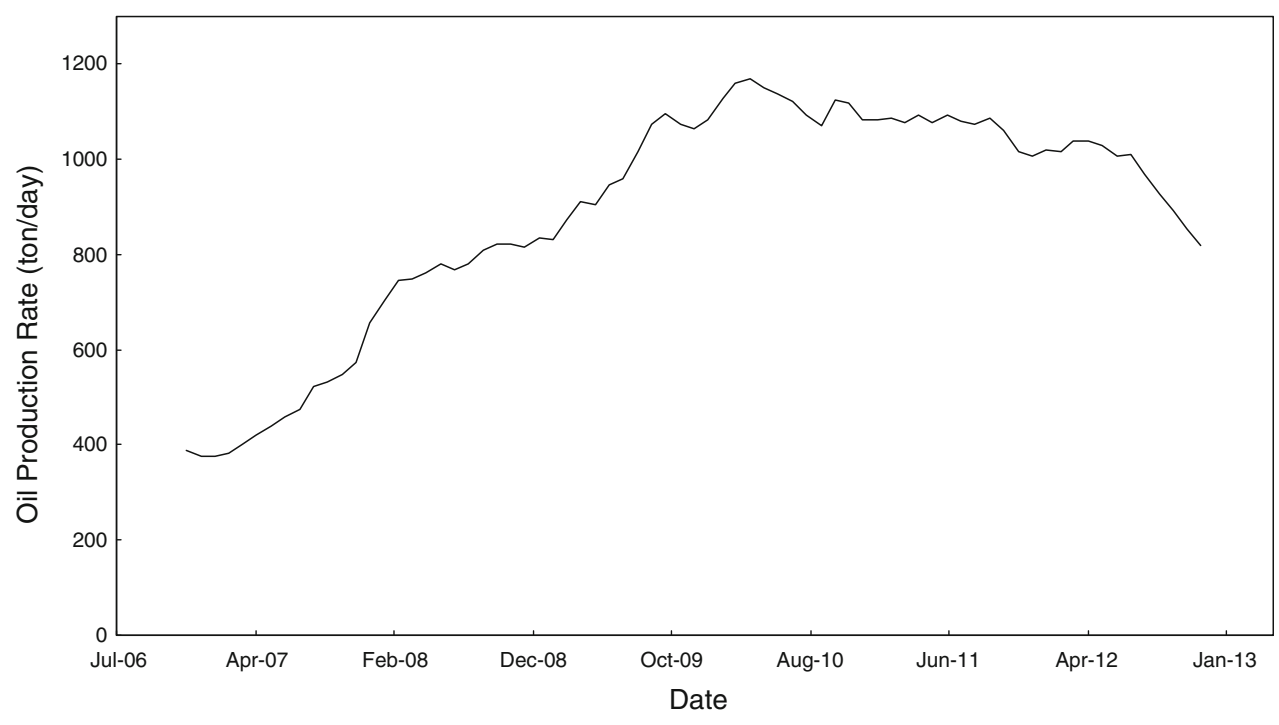

Table 6 Typical reservoir parameters for Shengtuo field

\begin{tabular}{ll}
\hline Reservoir depth $(\mathrm{m})$ & $1,899-2,060$ \\
Reservoir thickness $(\mathrm{m})$ & 13.6 \\
Reservoir temperature $\left({ }^{\circ} \mathrm{C}\right)$ & 80 \\
Reservoir permeability $(\mathrm{md})$ & $4,800-9,100$ \\
Oil density in situ $(\mathrm{g} / \mathrm{mL})$ & $0.78-0.86$ \\
Oil viscosity in situ $(\mathrm{cP})$ & $10-40$ \\
Oil density at surface $(\mathrm{g} / \mathrm{mL})$ & 0.93 \\
Oil viscosity at surface $(\mathrm{cP})$ & $100-3,000$ \\
Formation water salinity $(\mathrm{mg} / \mathrm{L})$ & 21,000 \\
Injected water salinity $(\mathrm{mg} / \mathrm{L})$ & 12,400 \\
\hline
\end{tabular}

sweep efficiency. Third, constant field monitoring and accurate field implementation are crucial.

Above all, polymer flood should be conducted when the reservoir oil saturation is still high. At Gudong field, polymer flood resulted in very different performance for two blocks with similar reservoir parameters. The tertiary oil recovery was $8.6 \%$ for the reservoir with higher oil saturation. However the tertiary recovery was only $4.4 \%$ for the other block (Zhang et al. 2001). The effect of polymer injection is more pronounced for the block with high oil saturation.

\section{Polymer viscosity}

The properties of injected polymer play an important role in the success of polymer flood projects. The polymer must satisfy a few requirements, including good solubility in water and good injectivity. Besides, polymer viscosity has been recognized as the major factor that influences the tertiary recovery. If polymer viscosity is low, sweep efficiency will be reduced and oil recovery will be compromised (Gao 2013).

This issue has been studied for decades. It was learnt that divalent ions, monovalent ions, shearing, high temperature, oxygen, and certain bacteria all have negative impacts on polymer viscosity (Mungan 1972; Maerker 1975; Ward and Martin 1981; Lee et al. 2009). Therefore, the quality of base water and formation water deserves much attention. At Shengli field, the earlier polymer flood projects targeted reservoirs with low salinity. As mentioned in previous sections, the formation water salinity at Gudao and Gudong field was well below 10,000 mg/L. The more recent polymer project has to face water salinity that exceeded $20,000 \mathrm{mg} / \mathrm{L}$. Future polymer flood projects have to face the challenges of harsh reservoir conditions.

At Shengtuo field, polymer was mixed with produced water to save fresh water resources. The salinity of fresh water was $680 \mathrm{mg} / \mathrm{L}$, while that for the produced water was as high as $12,000 \mathrm{mg} / \mathrm{L}$. It was observed that the polymer viscosity at injection wellhead dropped from 46 to $24 \mathrm{cP}$ (Li 2004). This case demonstrated the significance of water quality.

At Chengdong field, HPAM solution was prepared with produced waste water to reduce cost from water treatment. From 2004 to 2005 , the polymer solution maintained a viscosity around $20 \mathrm{cP}$, but quickly declined to $1-5 \mathrm{cP}$ in 2006 after waste water was introduced. After water analysis, it was found that the concentration of $\mathrm{Ca}^{2+}, \mathrm{Mg}^{2+}, \mathrm{K}^{+}$ and $\mathrm{Na}^{+}$ions in the base water remained stable, however the concentration of $\mathrm{Fe}^{2+}$ ions and $\mathrm{H}_{2} \mathrm{~S}$ increased significantly. Further lab tests showed that when $\mathrm{Fe}^{2+}$ concentration increases from 0 to $4 \mathrm{mg} / \mathrm{L}$, the polymer viscosity dropped from more than $200 \mathrm{cP}$ to less than 
Fig. 8 Production history of Shengtuo No. 1 unit

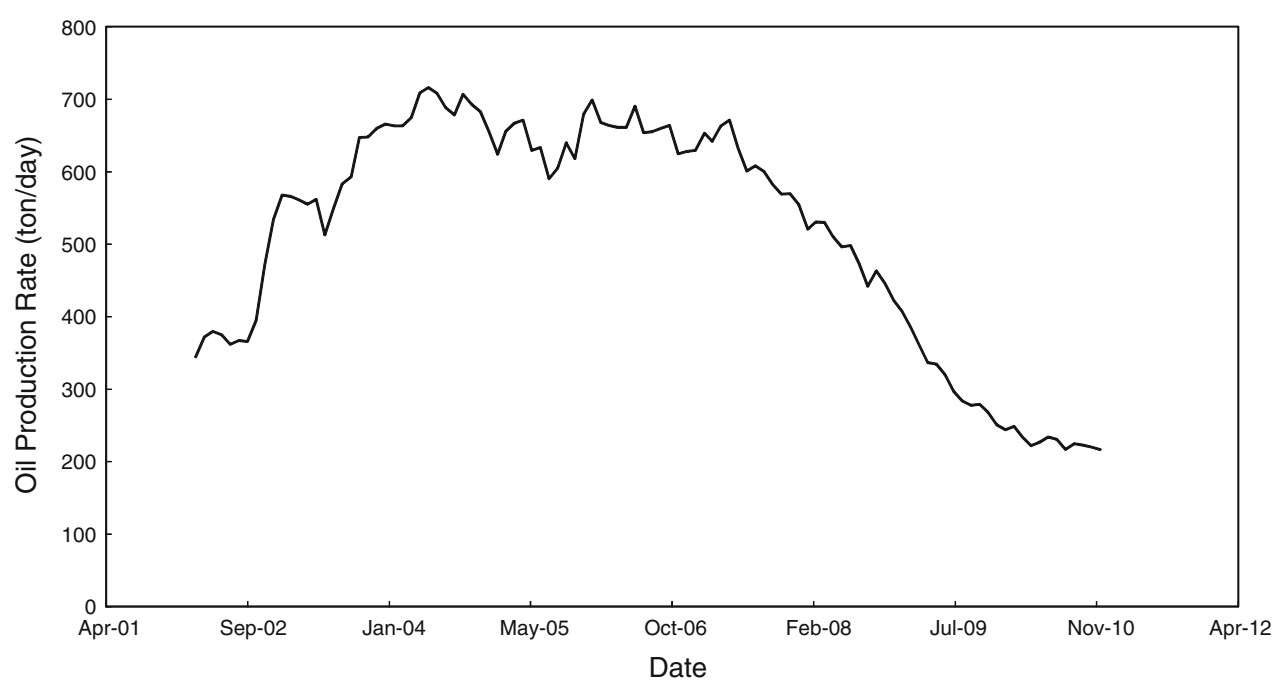

$50 \mathrm{cP}$. A microbe strain T. Thiooxidans was introduced into the waste water to reduce the harmful ions and $\mathrm{H}_{2} \mathrm{~S}$. After treatment, the polymer viscosity stabilized at around $25 \mathrm{cP}$ (Wang et al. 2012).

Based on the field experiences at Shengli field, the recommended polymer concentration is 1,500 to $2,000 \mathrm{ppm}$ to achieve good polymer viscosity. Second, the injection rate should be significantly lower than that for routine water flooding. This will reduce the effect of shearing and to help forming oil bank. Third, the injected polymer volume was often between 0.4 and $0.6 \mathrm{PV}$ to achieve good sweep efficiency. For SP flood, petroleum sulfonate alone could not achieve ultra-low interfacial tension. Therefore, sulfonate was often combined with nonionic surfactants. Typical recipe was $0.3-0.45 \%$ of sulfonate plus $0.1-0.15 \%$ of nonionic surfactants.

\section{Reservoir heterogeneity}

If high-permeability streaks exist in reservoir, the injected polymer solution will channel through these zones. As a result, the polymer fluid will not effectively sweep oil. A polymer flood was carried out at Gudong field's No. 7 unit from 1994 to 1997. The water cut declined from 95 to $90 \%$, and the daily oil output increased from 250 to 575 ton. The tertiary recovery was $5.75 \%$ (Jiang and Zhao 2001).

This result was however lower than expectation, because many high-permeability streaks exist in this block. Some production wells produced fluid whose polymer concentration was close to the injected polymer fluid. This clearly shows that polymer channeling occurs between the production and injection wells. Some wells had to be shut into retard channeling. Moreover, gel treatments were conducted to modify the conformance.
Project implementation

Close monitoring and accurate implementation play an important role in the successes of polymer projects. Polymer viscosity and concentration should be constantly monitored. For a polymer project at Gudao field, the polymer viscosity at injector wellhead showed abnormal oscillations. This issue was investigated and it was found that the fluid dilution operations did not abide by the standard procedures. Polymer concentration at the production wells also deserves much attention. If the produced polymer concentration is very low, certain factors may have caused the polymer fluid to degrade or divert. Otherwise, if the polymer concentration is very high, there probably exist high-permeability zones in the reservoir.

It is also worth mentioning that based on experiences at Shengli field, close well spacing is beneficial for polymer projects. The well spacing at Shengli is only $100-150 \mathrm{~m}$. The close well spacing is helpful for efficient monitoring and prompts adjustments in case the project design needs to be modified.

\section{Conclusion}

At Shengli field, the declining oil production and high water cut motivated trials of polymer flood. Since 1992, more than 60 field trials of polymer flooding and SP flooding techniques were applied at Shengli field and very positive results were achieved. Most polymer injection projects saw obvious increases in oil production rate, decreases in water cut, and improved oil recovery. The positive effects often lasted several years.

Based on field experiences, the major challenge facing polymer flood is loss of polymer viscosity under reservoir 
conditions, especially high water salinity and hardness. Future research will focus on developing more resilient polymers and understanding the flow of polymer in porous media.

Open Access This article is distributed under the terms of the Creative Commons Attribution License which permits any use, distribution, and reproduction in any medium, provided the original author(s) and the source are credited.

\section{References}

Gao C (2010) Scientific research and field applications of polymer flood in heavy oil recovery. J Petrol Explor Prod Tech $3(1): 65-70$

Gao C (2013) Viscosity of partially hydrolyzed polyacrylamide under shearing and heat. J Petrol Explor Prod Tech. doi:10.1007/ s13202-013-0051-4

Green DW, Willhite GP (1998) Enhanced oil recovery., SPE textbook series vol.6Society of Petroleum Engineers, Texas USA, pp 107-117

Jiang YB, Zhao W (2001) An industrial scale filed pilot study for polymer flood of Gudong Oilfield. Xin Jiang Petrol Geo 22(1):63-65

Lee S, Kim DH, Huh C, Pope GA (2009) Development of comprehensive rheological property database for EOR polymers. In: SPE 124798 presented at Annual Conference and Exhibition, New Orleans USA, 4-7, October 2009

Li ZQ (2004) The progress on polymer flooding test in Shengli Shengtuo Oilfield. China Petrol Process Petrochem Technol 35(10):56-59

Luo JH, Pu RY, Zhu HJ, Wang PM, Liu YZ (2004) Property and application of comb shaped polyacrylamide. Acta Petrolei Sinica 25(2):65-69
Maerker JM (1975) Shear degradation of partially hydrolyzed polyacrylamide. SPE J 15(4):311-322

Morel D, Vert M, Bouger Y (2010) First polymer injection in deep offshore field Angola. In: SPE 135735 presented at the Annual Technical Conference and Exhibition, Florence Italy, 19-22 September 2010

Mungan H (1972) Shear viscosity of ionic polyacrylamide solutions. SPE J 12(6):469-473

Sheng J (2010) Modern chemical enhanced oil recovery: theory and practice. Gulf Professional Publishing, Oxford UK, pp 101-111

Sun HQ, Zhang YG, Cao XL (2002) Polymer enhanced oil recovery technology. University of Petroleum Publishing, China, pp 282-289

Wang YQ (2007) Optimization of binary combination oil displacement system after polymer flooding in Shengli Oilfield. Petrol Drill Tech 35(5):101-103

Wang XZ, Zeng LF (2008) Effect of practical techniques in producing remaining oil in Gudong Oilfield. Petrol Explor Dev 35(4): $467-475$

Wang HY, Cao XL, Zhang JC, Zhang AM (2009) Development and application of dilute surfactant-polymer flooding system for Shengli Oilfield. J Petrol Sci Eng 65(1):45-50

Wang XZ, Wang JY, Zeng LF (2010) Surfactant polymer flooding pilot test in Gudong Oilfield. Petrol Geol Oilfield Dev Daqing 29(5):151-153

Wang WD, Lin JZ, Geng LL, Du CA, Yuan CZ, Song ZY (2012) Waste water treatment for polymer injection at Chengdong field. Oilfield Surf Eng 31(20):19-21

Ward JS, Martin FD (1981) Prediction of viscosity for partially hydrolyzed polyacrylamide solutions in the presence of calcium and magnesium ions. SPE J 21(5):623-631

Wassmuth FR, Arnold W, Green K, Cameron N (2009) Polymer flood application to improve heavy oil recovery at East Bodo. J Can Pet Technol 48(2):55-61

Zhang YG, Yuan FQ, Guo LL, Jiang YB (2001) Research on influence factors of polymer flooding in Shengli Oilfield. J Southwest Pet Inst 23(3):50-53 